\title{
Hortifrutigranjeiros e o debate do Novo Código Florestal: Impacto da geração de renda e qualidade de vida da comunidade do Cinturão Verde no Estado do
}

\section{Maranhão}

\author{
Fruits and vegetables and the debate of the New Forest Code: Impact of income generation and \\ quality of life of the Green Belt Community in the State of Maranhão \\ Frutas y hortalizas y el debate del Nuevo Código Forestal: Impacto de la generación de ingresos y \\ calidad de vida de la comunidad del Cinturón Verde en el Estado de Maranhão
}

Recebido: 29/03/2021 | Revisado: 08/04/2021 | Aceito: 09/04/2021 | Publicado: 18/04/2021

\author{
Beatriz de Aguiar do Nascimento \\ ORCID: https://orcid.org/0000-0003-0993-1859 \\ Universidade Estadual do Maranhão, Brasil \\ E-mail: beattryz_ev@hotmail.com \\ Luciana Sousa da Silva \\ ORCID: https://orcid.org/0000-0003-1372-6364 \\ Universidade Estadual do Maranhão, Brasil \\ E-mail: lucianasilva.agro@gmail.com \\ Rayssa Kellen dos Santos Costa \\ ORCID: https://orcid.org/0000-0002-2047-7389 \\ Universidade Estadual do Maranhão, Brasil \\ E-mail: rayssakellen02@gmail.com \\ Camila Alexandre Cavalcante de Almeida \\ ORCID: https://orcid.org/0000-0002-2989-8243 \\ Universidade Federal de Alagoas, Brasil \\ E-mail: mil.la.m@hotmail.com \\ Denise Maria Santos \\ ORCID: https://orcid.org/0000-0001-8886-6439 \\ Instituto Dom José de Educação e Cultura, Brasil \\ E-mail: deniseufc@yahoo.com.br \\ Alexsandro Gonçalves Pacheco \\ ORCID: https://orcid.org/0000-0003-1888-0360 \\ Universidade Federal de Alagoas, Brasil \\ E-mail: alex.pacheco@live.com \\ Maria José de Holanda Leite \\ ORCID: https://orcid.org/0000-0003-4154-3901 \\ Universidade Estadual do Maranhão, Brasil \\ E-mail: maryholanda@gmail.com
}

\begin{abstract}
Resumo
A presente pesquisa teve como objetivo avaliar a geração de renda e qualidade de vida dos hortifrutigranjeiros da microrregião aglomeração urbana de São Luís-MA. Para responder a nossa hipótese de trabalho, procurou-se entender quais as barreiras enfrentadas, se recebem assistência técnica, apoio fiscal e uso de novas tecnologias. A elaboração do trabalho se deu com base em revisões bibliográficas e caracterização ambiental do Cinturão verde, foi realizada mediante visitas e aplicação de questionários referente ao novo código florestal. O público alvo foi os hortifrutigranjeiros que atuam na área, os quais representam um papel de grande importância para a sua cidade pois boa parte das hortaliças, frutíferas e aves produzidas são consumidas e vendidas em feiras da região. Com resultado, foi possível concluir que, a comunidade enfrenta um sério problema com a falta da água, uma vez que este recurso é essencial para o trabalho agrícola. A agricultura familiar no Cinturão Verde mostra-se em uma situação vulnerável, em busca de apoio, e investimentos do governo. Tivemos a oportunidade de conhecer a realidade desses agricultores, que ainda lhe faltam conhecimento sobre o novo código florestal que visa na melhoria dos agricultores. Com base nas dificuldades expostas na pesquisa, recomenda-se que o estado e governo se sensibilizem e ajudam esses produtores a continuarem com seus trabalhos, disponibilizando apoio, assistência técnica, e investimentos em novos programas que os auxiliam e façam crescer para melhorar os seus produtos, a sua fonte de renda, dando aos mesmos uma vida digna e saudável.
\end{abstract}

Palavras-chave: Sustentabilidade; Produção; Ecologia; Legislação. 


\begin{abstract}
This research aimed to evaluate the income generation and quality of life of horticultural fruits of the São Luís-MA urban agglomeration micro-region. To answer our working hypothesis, we sought to understand what barriers are faced, whether they receive technical assistance, fiscal support and the use of new technologies. The preparation of the work was based on bibliographic reviews and environmental characterization of the Green Belt, was carried out through visits and application of questionnaires referring to the new forest code. The target audience was the fruit and vegetable growers who work in the area, which play a very important role for your city because a large part of the vegetables, fruit and poultry produced are consumed and sold at fairs in the region. As a result, it was possible to conclude that the community faces a serious problem with the lack of water, since this resource is essential for agricultural work. Family farming in the Green Belt shows itself to be in a vulnerable situation, seeking support and government investments. We had the opportunity to get to know the reality of these farmers, who still lack knowledge about the new forest code that aims to improve farmers. Based on the difficulties exposed in the research, it is recommended that the state and government are sensitized and help these producers to continue their work, providing support, technical assistance, and investments in new programs that help them and grow to improve their products., their source of income, giving them a dignified and healthy life.
\end{abstract}

Keywords: Sustainability; Production; Ecology; Legislation.

\begin{abstract}
o
Esta investigación tuvo como objetivo evaluar la generación de ingresos y la calidad de vida de los frutos hortícolas de la microrregión de aglomeración urbana São Luís-MA. Para responder a nuestra hipótesis de trabajo, buscamos comprender qué barreras se enfrentan, si reciben asistencia técnica, apoyo fiscal y el uso de nuevas tecnologías. La elaboración del trabajo se basó en revisiones bibliográficas y caracterización ambiental del Cinturón Verde, se llevó a cabo mediante visitas y aplicación de cuestionarios referentes al nuevo código forestal. El público objetivo fueron los productores hortofrutícolas que laboran en la zona, los cuales juegan un papel muy importante para su ciudad porque gran parte de las hortalizas, frutas y aves producidas se consumen y comercializan en ferias de la región. Como resultado, se pudo concluir que la comunidad enfrenta un serio problema con la falta de agua, ya que este recurso es fundamental para el trabajo agrícola. La agricultura familiar en el Cinturón Verde se muestra en una situación de vulnerabilidad, buscando apoyo e inversiones gubernamentales. Tuvimos la oportunidad de conocer la realidad de estos agricultores, quienes aún carecen de conocimiento sobre el nuevo código forestal que tiene como objetivo mejorar a los agricultores. Con base en las dificultades expuestas en la investigación, se recomienda que el estado y el gobierno se sensibilicen y ayuden a estos productores a continuar su trabajo, brindándoles apoyo, asistencia técnica e inversiones en nuevos programas que los ayuden y crezcan para mejorar sus productos. su fuente de ingresos, brindándoles una vida digna y saludable.
\end{abstract}

Palabras clave: Sostenibilidad; Producción; Ecología; Legislación.

\title{
1. Introdução
}

O novo código florestal, Lei 12.651 de 25 de maio de 2012, trouxe mudanças que causaram uma série de discussões, e que ainda se estendem até hoje. As justificativas para as mudanças propostas foram diversas, dentre elas a falta de áreas agricultáveis no Brasil, que o código engessa o crescimento da agropecuária brasileira, de não possuir base científica, além de prejudicar a agricultura familiar (Rebelo, 2010). Das mudanças mais impactantes vale salientar a redução da extensão das faixas de Áreas de Proteção Permanente (APP) para rios, que excluem não só as matas ciliares, bem como áreas de várzea da proteção já que a delimitação do leito de um rio passa a ser a partir do leito regular, aquele por onde corre água durante todo o ano, e não mais o leito sazonal de maior cheia, toda a extensão de área que alaga durante a época de chuva (S.O.S. Florestas, 2011).

Sabe-se que, a insuficiência da assistência técnica e extensão diante da demanda da agricultura familiar são evidenciadas a nível nacional, restringindo as possibilidades das famílias em ter acesso a conhecimentos, resultados de pesquisas voltadas ao setor e as políticas públicas de modo geral, contribuindo para a ampliação da diferenciação e exclusão social (Ministério do Desenvolvimento Agrário, 2004).

Segundo a literatura, em 2011 foi criado um projeto de Lei (174/11) conhecido como Plano Nacional de Hortigranjeiros (PlanHort), o qual teve como objetivo estimular à produção e o consumo de hortaliças, frutas, flores, plantas ornamentais e medicinais, produtos alimentícios naturais e perecíveis, pescados e víveres. Este também busca também promover o desenvolvimento e a difusão de técnicas e boas práticas de produção, transporte, embalagem, armazenagem e comercialização dos produtos naturais. Segundo Araújo, Godrim e Souza (2007), as comunidades buscam se organizar a fim de atender as próprias 
necessidades, melhorando assim suas condições de vida. Onde a necessidade de se organizar surge quando aparecem vontades ainda não satisfeitas e que não têm solução a curto ou médio prazo a partir de atitudes individuais.

A pressão sofrida pelo capitalismo foi então sentida com afinco pelos agricultores familiares, pois esses mesmos se deparam com muitos desafios, já que os consumidores mediante o desenvolvimento regional ficam cada vez mais exigentes, logo os agricultores familiares se deparam com limitações para se inserir no mercado, sem ter destino certo para sua comercialização. Destino esse, que possa se caracterizar como uma forma justa de vender seus produtos (Azevedo 2015). Com isso o agricultor familiar sente a necessidade de se adaptar as exigências ditadas pelos consumidores, e a buscar espaço para seus produtos, porém precisam se adaptar as tendências e imposições desse sistema econômico vigente, já que sofrem com a deficiência de incentivo e auxílio, eles lutam individualmente ou em grupos para mudar essa realidade (Azevedo 2015)

É conhecido que, a agricultura familiar nos últimos anos obteve muitos trabalhos relacionados as suas políticas de desenvolvimento, deixando claro os avanços e direções que várias famílias estão traçando nesse período. A agricultura familiar no Brasil sempre constituiu uma categoria ainda marginalizada pelo Estado e também pela própria sociedade, principalmente no que se refere a novas políticas agrícolas, aquisição de maquinas e novas tecnologias (Lima et al., 2019). Produtores agrícolas estão vivenciando muitos problemas que a muito tempo buscam solucionar, famílias estão desanimadas a continuarem com seus trabalhos, pois lhe faltam retornos por conta da pandemia Covid19 ficou claro que governos e Estados os abandonaram e não se preocuparam que o único meio de sobrevivência da grande maioria depende integralmente da agricultura.

Vale ressaltar que, durante um prolongado período de nossa história, o interesse em desenvolver a agricultura estava voltado somente para os grandes produtores rurais, considerando assim essa atividade familiar como um atraso para o desenvolvimento nacional (Braga, 2013; Delgado, 2017). A grande maioria dos pequenos agricultores não tem apoio, assistência técnica ou investimentos, para os auxiliares no melhor desenvolvimento dos seus trabalhos, levando aos membros mais jovens, que vão em busca de melhor educação se deparam com uma realidade mais prática na cidade, e poucos retornam para seu local de origem. É por isso que a atividade tem seu ritmo lento, pois cada vez mais as famílias têm contado com menos mão de obra

Segundo o Secretário da SAF "Adelmo Soares", o Maranhão tem abundância de água, o problema é a falta de armazenamento. A água é um elemento da natureza de extrema importância para o agricultor familiar, para a produção de alimentos. Na comunidade do Cinturão Verde, moradores que vivem da produção agrícola, reclamam da ausência de água, elemento essencial a produção agrícola.

No estado do maranhão os produtores rurais buscam reconhecimento pelos seus trabalhos, famílias dependem das suas produções para sobreviver. Preços para a Agricultura Familiar (PGPAF). O desconto é concedido aos produtos que tiveram o valor de mercado abaixo do preço de garantia, definido com base no custo de produção. A realidade é que a cada dia se torna difícil ter mercado para seus produtos, pois os mesmos não atendem a perfeição que o comercio busca, logo porque não tem incentivos e assistência a esses produtores para terem um produto de melhor qualidade, sendo ele livre de pragas e doenças. Ao invés disso oferecerem a oportunidade para grandes produtores de regiões e estados diferentes, e quando ficam com a mercadoria o valor que as oferecem é baixo, causando prejuízos a esses produtores que não tem outra alternativa a não ser vender pelo preço baixíssimo.

A comunidade agrícola "Cinturão Verde", teve origem na união de produtores rurais. Em 24 de agosto de 1997 fundaram uma associação e buscaram a compra de uma área onde fosse possível agregar a produção agrícola e as atividades gerais. Essa decisão se deu, em parte, pelos incentivos que os gestores municipais da época começavam a oferecer (Irineu et al., 2005). A comunidade é composta por mais de 80 (oitenta) famílias as quais as maiorias vivem de produção agrícola, que produzem na própria comunidade e são comercializadas nas feiras da cidade.

Desse modo, nossa pesquisa teve como objetivo principal avaliar a geração de renda e qualidade de vida dos hortifrutigranjeiros da comunidade do Cinturão Verde na zona rural de São Luís-MA, procurando entender quais as barreiras são 
enfrentadas, se recebem assistência técnica, apoio fiscal, uso de novas tecnologias. Também se buscou analisar o nível de conhecimento desses agricultores sobre as normas do novo código florestal.

\section{Material e Métodos}

A pesquisa foi realizada no município de São Luís do Maranhão, na comunidade do Cinturão Verde (Figura 1), entre o mês de janeiro a fevereiro de 2021. A área tem aproximadamente 383 hectares, com solo arenoso. Na região moram mais de 80 (oitenta) famílias que exercem atividades agrícolas, produzem hortaliças, frutíferas e granjas que comercializam nas principais feiras da capital.

Figura 1. Microrregião Aglomeração Urbana de São Luís - Maranhão, Cinturão Verde.

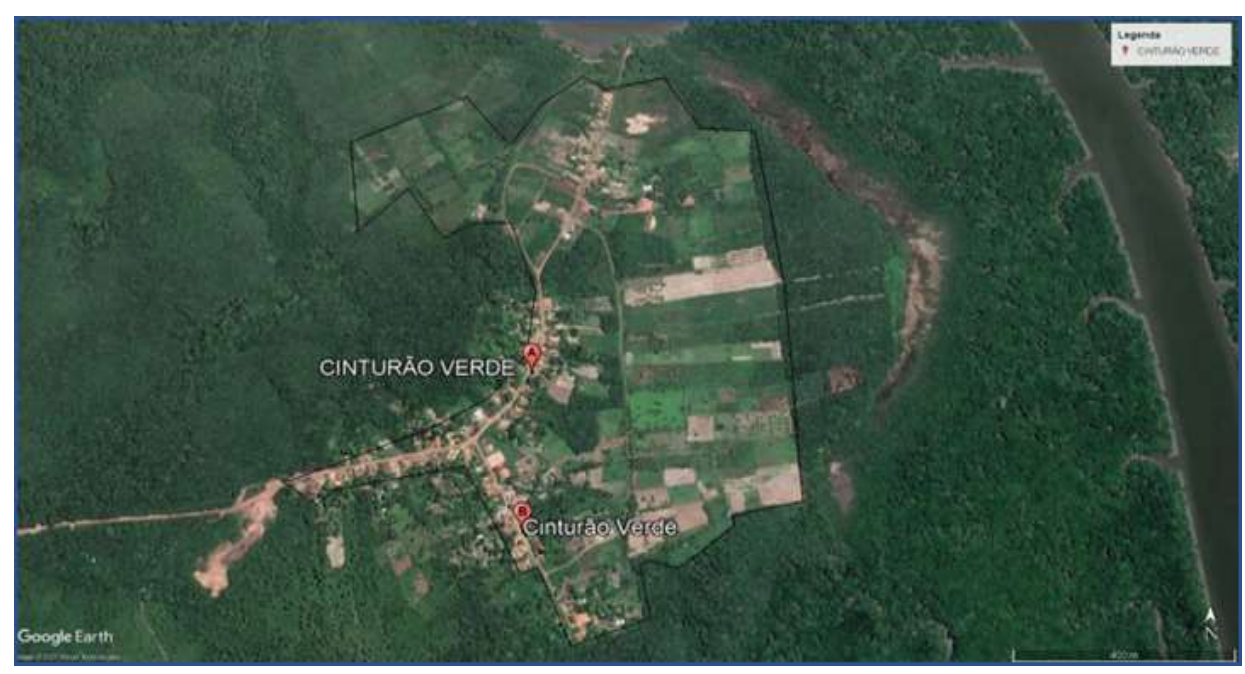

Fonte: (Google Earth, adaptado Por Rodrigues Junior, L. A. R., 2021).

A elaboração do trabalho se deu com base em revisões bibliográficas referente ao tema, e com a finalidade de caracterizar os aspectos ambientais do Cinturão verde, mediante a realização de visita e aplicação de um questionário, foi possível a obtenção de informações relevantes para elaboração do trabalho.

As perguntas realizadas foram as seguintes: a) você como horticultor tem conhecimento do que é o código florestal? b) você acha que o uso da tecnologia facilita o desenvolvimento dos horticultores ao uso do código florestal?; c) os horticultor da sua região tem o acompanhamento de fiscalização com frequência?; d) de que forma ocorreu essa adaptabilidade de horticultores ao novo código florestal?; e) como horticultor você já visualizou a melhoria decorrente a aplicação do novo código florestal?; f) o cumprimento do novo código florestal influenciou na produção em termo de quantidade produtiva?; g) você como horticultor que tem conhecimento do código florestal concorda com as alterações do novo código florestal?; h) os fiscais compareceram para informar e tirarem dúvidas sobre o código florestal ?; i) você se preocupa com uma lei que trata de florestas como horticultor?; j) como horticultor você acha que essa mudança pode intervir nos seus ganhos econômicos?; 1) você sabia que o novo código florestal passou por um longo processo até a sua aprovação no ano de 2012 ?

O público alvo deste trabalho, foram os hortifrutigranjeiros que aturam na área do Cinturão Verde, situado na zona rural de São Luís, apresentando um papel de grande importância para a sua cidade pois boa parte das hortaliças, frutíferas e aves produzidas são consumidas e vendidas em feiras da região.

Esse trabalho visa ajudar aos hortifrutigranjeiros a serem vistos como partes fundamentais para o nosso município e estado, mostrando a realidade que se é passado por cada produtor e família que dependem da agricultura rural. 
Vale ressaltar que uma pesquisa qualitativa "como a nossa" é capaz de relatar, através de observações, análise de sentimentos, percepções e intenções que dados podem ser mensurados e captados para informar ao público seja ele alvo ou não, que não é apenas numericamente que se pode ser feito um trabalho.

A pesquisa utilizou os métodos quantitativos e qualitativos. Para Dalfovo et al. (2008), o método quantitativo caracteriza-se pelo emprego de quantificação, tanto nas modalidades de coleta de informações, quanto no tratamento desses por meio de técnicas estatísticas. O método qualitativo, se caracteriza por um maior foco na compreensão dos fatos.

Após a coleta dos dados, foi realizada a análise estatística. Todas as análises foram realizadas através dos Programas Excel (Microsoft Office Excel). A análise estatística foi realizada através do cálculo da média e taxas percentuais das variáveis analisadas. Em seguida organizados por meio de gráficos e tabelas para melhor compreensão da real situação dos hortifrutigranjeiros que atuam no Cinturão Verde.

\section{Resultados e Discussão}

Com base nos resultados obtidos durante a pesquisa através da aplicação de questionários, foi possível constatar que os produtores do Cinturão verde, estão passando por várias situações de calamidade. Sendo um dos principais relatos a falta de investimentos, assistência técnica, comercialização dos produtos e a falta da água.

Durante a aplicação dos questionários, referente ao novo código florestal, a equipe teve muita dificuldade em entrevistar os produtores. Em uma comunidade com mais de 80 famílias, só foi possível aplicar o questionário com apenas 8 pessoas, um número muito baixo, sendo que das 8 pessoas nenhuma souberam responder as perguntas relacionada o novo código florestal (Figura 2), por falta de conhecimento sobre o assunto abordado, no entanto realizou-se entrevistas, em que essas pessoas relataram muitas dificuldades por conta dessa falta de assistência na comunidade, vale ressalta que o local é de difícil acesso e com pouca mobilidade de transporte público, o qual funciona uma vez na semana, mais precisamente aos domingos.

Figura 2. Conhecimento dos produtores sobre o novo Código Florestal e barreiras da comunidade do Cinturão Verde.

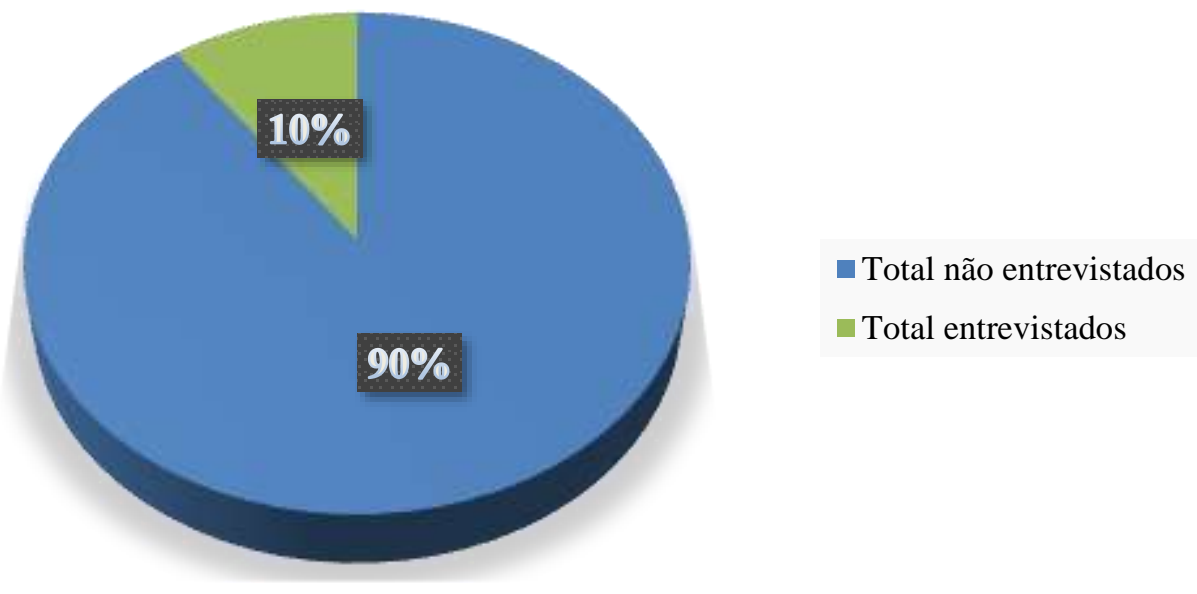

Fonte: Autores

Os investimentos que esses produtores recebem também é escasso, eles buscam e correm atrás a anos para a melhoria da comunidade, nisso os seus produtos se tornam pouco competitivos, pois são alvos de pragas e doenças que alguns controles viáveis não solucionam, gerando assim um produto pouco desejado nas prateleiras de feirantes e supermercados que acabam optando por produtos de fora, de grandes produtores, que acaba saindo por um valor bem baixo. O que mais uma vez dificulta a vida desses agricultores que acabam negociando a sua mercadoria por um valor muito baixo. 
A comunidade também enfrenta problemas com a falta da água, uma vez que este recurso é essencial para o trabalho agrícola. As famílias só têm direito a 2 horas de água por dia que é usada para beber, cozinhar, banhar e irrigar, porque os poços que tem na comunidade apenas um é ligado para distribuir a água, justamente porque essas famílias não têm condições de no final do mês pagar pela água e pela energia caríssima que é gerada.

Com essa falta de água os produtores possuem uma grande dificuldade quanto a irrigação, pois não a condições de manter um plantio sem água. Foi visto na visita que o reservatório de água já está sem oxigênio, cheia de algas como é possível observar na (Figura 3). A agricultura consome 87\% dos recursos hídricos mundiais, sendo assim a falta desse recurso causa um grande impacto na economia (Goellner, 2015). Então em uma comunidade que encaram nesse momento uma escassez de água se torna muito difícil de produzir e criar as suas futuras rendas. O número de pessoas que vivem em países com carência de água está projetado para subir de 500 milhões para 3 bilhões, em 2025 (Stockle,2001).

Ao decorrer da pandemia do COVID-19 os produtores tiveram que procurar uma nova maneira de gerar renda por conta da falta de comercialização, pois só $30 \%$ dos seus produtos são vendidos para um programa do governo estadual, que na qual esse valor é muito baixo, para se ter uma renda melhor os produtores vendem em feiras e faz entrega dos seus produtos para um determinado supermercado que na qual se o produto não for vendido todo é devolvido para o produtor e com isso os produtores tem um grande prejuízo, com descartes de produtos que acabam por estragar. Eles vendem também seus produtos na sua própria comunidade, que contém uma única banca, como podemos notar na (Figura 4). A fragilidade desses produtores no que diz respeito ao tamanho da propriedade, introdução de novas tecnologias e de investimentos na produção, agrava-se ainda mais quando chega o momento de vender a produção (Noronha \& Hespanhol, 2005).

Cabe fazer a ressalva que, durante um prolongado período de nossa história, o interesse em desenvolver a agricultura estava voltado somente para os grandes produtores rurais, considerando assim essa atividade familiar como um atraso para o desenvolvimento nacional (Braga, 2013; Delgado, 2017). A grande maioria dos pequenos agricultores não tem apoio, assistência técnica ou investimentos, para os auxiliares no melhor desenvolvimento dos seus trabalhos.

Figura 3. Tanque de criação de peixes de alguns produtores da comunidade Cinturão verde, zona rua do município de São Luís-MA.

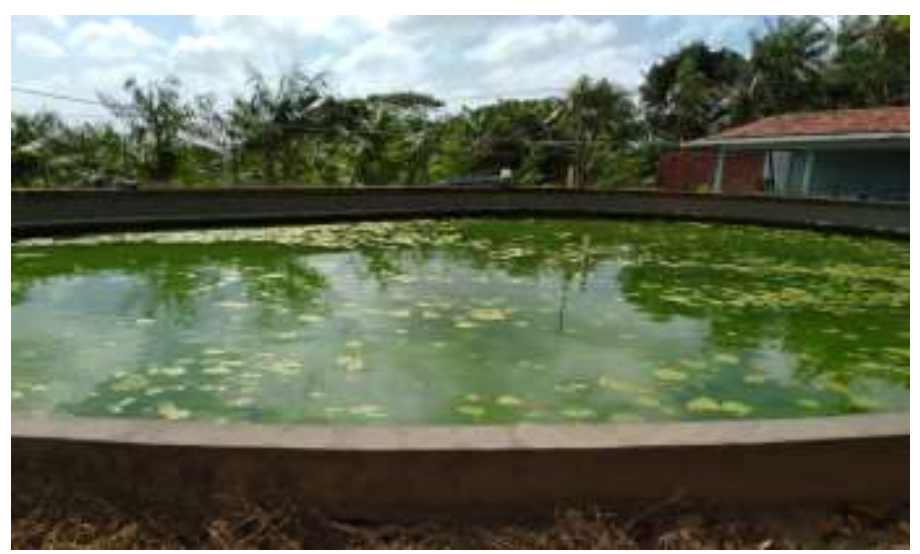

Fonte: Nascimento (2021).
Figura 4. Banca onde é colocado seus produtos para ser comercializado na comunidade.

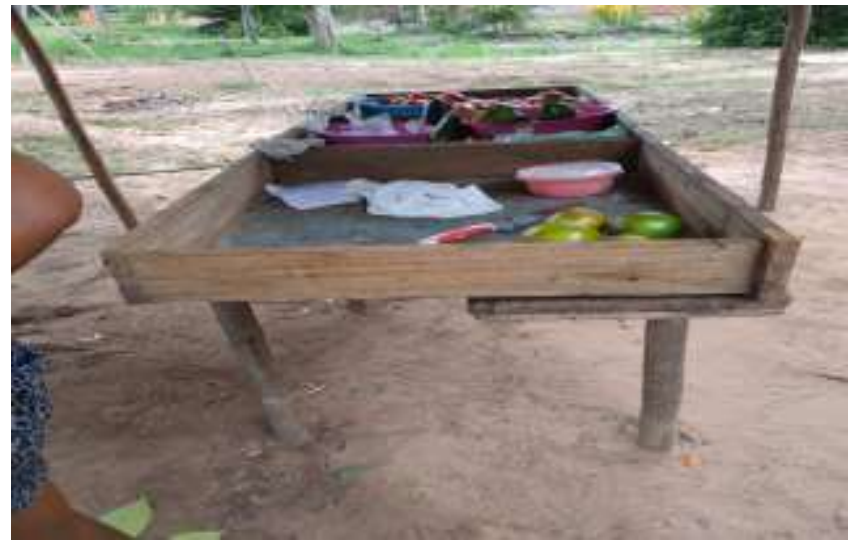

Fonte: Nascimento (2021).

O coentro é uma hortaliça amplamente consumida no Brasil e, apesar de ser considerada uma "cultura de quintal", grande número de produtores está envolvido com sua exploração, tornando-a consequentemente uma cultura de grande importância socioeconômica (Pereira, 2005). Essa hortaliça é bastante produzida no Cinturão Verde, podemos ver na (Figura 5), assim como também cebolinha, alface, couve, vinagreira pois são culturas de ciclo rápido. Então como pequenos agricultores 
não podem esperar muito, enquanto outras culturas terminam seu ciclo sendo mais demorado como mandioca, feijão (Figura 6), os produtores já têm outros produtos para ser comercializados.

Figura 5. Hortaliças cultivadas na comunidade do Cinturão verde.

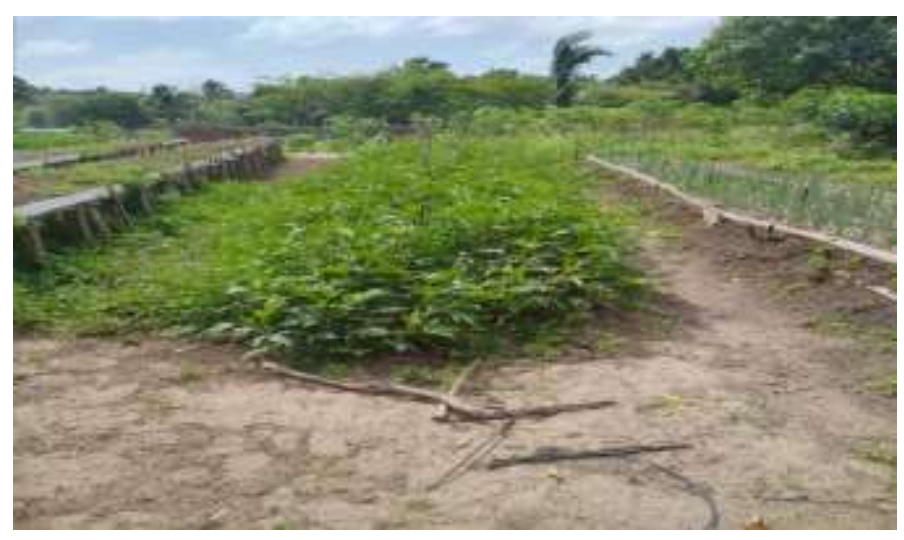

Fonte: Nascimento (2021).
Figura 6. Culturas de ciclo mais longo cultivadas na comunidade do Cinturão verde.

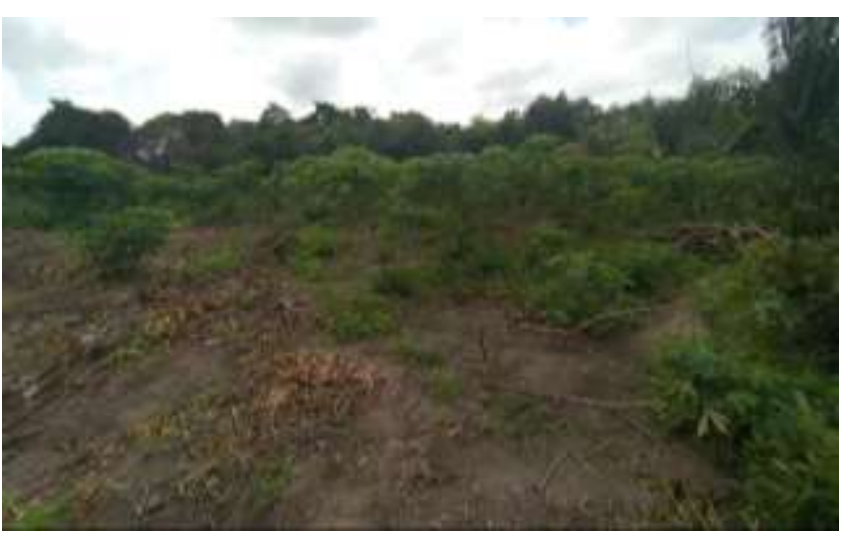

Fonte: Nascimento (2021).

A agricultura familiar no Cinturão Verde mostra-se em uma situação vulnerável, em busca de apoio, e investimentos do governo. Tivemos a oportunidade de conhecer a realidade desses agricultores, que ainda the faltam conhecimento sobre o novo código florestal que visa na melhoria dos agricultores. Os produtores rurais é uma classe que necessita desses incentivos, assistência técnica e um amplo mercado, tendo prioridade nas suas regiões e municípios. Que pode ser feito através de programas sociais, associações, órgãos e governos que invistam nessas famílias, seja desenvolvendo novas políticas públicas. Podemos concluir que a pesquisa demostrou um ramo de atividade que necessita muito da determinação e força para conseguir alcançar uma renda melhor, garantindo a sobrevivência e o futuro de suas famílias, além do mais eles amam o que fazem e por conta disso não desistiram. Portanto deve-se ser recomendado que o estado e governo se sensibilizem e ajudam esses produtores a continuarem com seus trabalhos, disponibilizando apoio, assistência técnica, e investimentos em novos programas que os auxiliam e façam crescer para melhorar os seus produtos, a sua fonte de renda, dando aos mesmos uma vida digna e saudável.

\section{Conclusão}

Por todos aspectos relatados, recomenda-se que o estado e governo invista em melhorias para os produtores rurais dessa região, dando apoio, assistência técnica e investimentos em novos programas que auxiliam os agricultores a ter um melhor produto e um amplo mercado.

\section{Referências}

Araújo, T. C. A., Godrim, M. D., \& Souza, V. S. A organização social da agricultura familiar do projeto Jaíba-MG como desafio para o desenvolvimento local sustentável. In: XLV Congresso da Sober, 2007, Londrina, PR. XLV Congresso da Sober. < http://www.sober.org.br/palestra/6/333.pdf>.

Azevedo, M. B. A. de. Análise sistêmica da comercialização de hortifrutigranjeiros em feiras de agricultura familiar dos territórios sertão do Apodi e AçuMossoró (RN). 2015.

Braga, C. L. Os impactos do programa de aquisição de alimentos para a agricultura familiar periurbana: o caso da comunidade do Cinturão Verde, São Luís/MA. Universidade Federal do Maranhão.

Dalfovo, M. S. et al. Métodos quantitativos e qualitativos: um resgate teórico. <http://www.ca.unisc.br/ portal/upload/com_arquivo/metodos_quantitativos_e_qualitativos_um_resgate_teorico.pdf>.

Delgado, G. C., \& Bergamasco, S. M. P. P. (orgs.) Agricultura familiar brasileira: desafios e perspectivas de futuro. Brasília: Ministério do Desenvolvimento Agrário. < http://www.sober.org.br/palestra/6/333.pdf>. 
Research, Society and Development, v. 10, n. 4, e48310414420, 2021

(CC BY 4.0) | ISSN 2525-3409 | DOI: http://dx.doi.org/10.33448/rsd-v10i4.14420

Goellner, C. O uso da água e a agricultura. s.l. Comitê de gerenciamento da bacia hidrográfica do Alto Jacuí <http://www.upf.br/coaju/index.php/informacoes/downloads/artigos?download=739: Artigo>

Ireneu, J. R., L. T. S., \& Conceição, S. P. Análise do processo de produção e comercialização agrícola na comunidade Cinturão Verde - zona rural de São Luís. São Luís: Faculdade São Luís, 2005.

Lima, A., Silva, E., \& Iwata, B. (2019). Agriculturas e agricultura familiar no Brasil: uma revisão de literatura. Retratos de Assentamentos. 22. 50. 10.25059/2527-2594/retratosdeassentamentos/ 2019.v22i1.332. Faculdade São Luís.

Metzger, J. P., Lewinsohn, T. M., Joly, C. A., Casatti, L., Rodrigues, R. R., \& Martinelli, L. A. Impactos potenciais das alterações propostas para o Código Florestal Brasileiro na biodiversidade e nos serviços ecossistêmicos. Documento-síntese produzido por Pesquisadores do Programa Biota-Fapesp e pela ABECO (Associação Brasileira de Ciência Ecológica e Conservação), Biota Neotropica, 10(4).

Ministério do Desenvolvimento Agrário (MDA). http://www.agerp.ma.gov.br/pgpaf-desconto-para-oito-produtos/.

Noronha, E. O., \& Hespanhol, R. A. M. O pequeno produtor rural e as estratégias de comercialização dos produtos hortícolas no Município de Presidente Prudente/SP. <http://www2.prudente.unesp.br/pos/geo/Gedra_2005/textouel.htm.>

Pereira, R. S., Muniz, M. F. B., \& Nascimento, W. M. Aspectos relacionados à qualidade de sementes de coentro. Horticultura Brasileira, 23(3), 703-706.

Rebelo, A. Parecer do relator deputado federal Aldo Rebelo (PCdoBSP) ao Projeto de Lei no $1876 / 99$ e apensados.

Sos Florestas. Código Florestal: entenda o que está em jogo com a reforma da nossa legislação ambiental. < http://d3nehc6y19qzo4.cloudfront.net/downloads/cartilha_codigoflorestal_2 0012011.pdf>.

Stockler, C. O. Environmental impact of irrigation: a review. Pullman: 